\title{
Impact of short yoga intervention on health science students' perceptions about yoga
}

\author{
Deshpande, A. and Chari, S.
}

\begin{abstract}
Introduction: Efficacy of yoga in health science education is well documented. It has shown to be beneficial for students at physical, psychological, social and spiritual levels. Aim of this study was to identify the beliefs and attitudes of health science students about yoga and to determine the impact of short yoga intervention on students' perceptions about yoga with respect to future yoga practice.

Methods: A structured questionnaire was administered to $1^{\text {st }}$ year medical, dental, physiotherapy and nursing students $(\mathrm{N}=278)$ for pre and post interventions. The intervention comprised of 10 hours yoga sessions including yoga postures, breathing exercises, meditation and yoga nidra. Guidance on healthy lifestyle and holistic wellbeing was also given.
\end{abstract}

Results: $97.2 \%$ students believed that yoga helps in keeping optimum fitness with balanced physical, mental and spiritual health. Students acknowledged various physical benefits of yoga, predominantly flexibility (97.3\%), stamina (94\%) and optimum weight (96.3\%). Relaxation (96.7\%), improved memory $(95.9 \%)$ and reduction in stress $(92.1 \%)$ were the dominant perceived psychological benefits. Perceived dominant barriers in practicing yoga weretime management $(71.9 \%)$ and lack of motivation $(65.1 \%)$. There was significant difference in the motivation and time management for yoga in pre and post intervention ( $p$ value $<0.001$ ).

Conclusion: Health science students had overall positive attitude towards yoga and health. Short yoga interventions did not have significant impact on perceptions of students about benefits of yoga, but helped to overcome barriers by providing motivation and effective time management. Incorporating yoga in health science education will help future professionals to adopt positive health and disseminate the same to their patients and community.

Key Words: Perceptions, Yoga, Students, Health Science Education, Intervention

\section{Introduction}

In India, the undergraduate medical education is designed with a goal to create an "Indian Medical Graduate" who must be able to understand and provide preventive, promotive, curative, palliative and holistic care with compassion.

\footnotetext{
${ }^{1}$ Director, Padma Yog Sadhana, a unit of Terna Pubic Charitable Trust, Navi Mumbai, Maharashtra, India

${ }^{2}$ Professor, Director, Research and MET Unit, NKP Salve Institute of Medical Sciences, Nagpur, Maharashtra, India

Corresponding Author:

Dr. Anjali Deshpande,

Above auditorium, Terna Dental College, Sector 22, Plot

12, Opposite Nerul Railway Station, Nerul West, Navi

Mumbai 400706, Maharashtra, India

Email:dranjali145@gmail.com
}

The Regulations on Graduate Medical Education, 2012 released by the Medical Council of India have made it mandatory for students to undergo a foundation course including yoga and sports (Medical Council of India, 2012).

Yoga, is more than 5000 year old Indian philosophy which is the spiritual and cultural heritage of India. Yoga makes the body healthier, the mind calmer and more controlled, helping towards self-realisation.

Efficacy of yoga in health science education is well documented in the literature. Several studies carried out in medical, dental, physiotherapy and nursing institutes in India and other countries determine the efficacy of yoga in health science education. It has shown to be beneficial for students at physical, psychological, social and spiritual levels and also for better academic performance (Simard \& Henry, 2009; Shankarapillai, 2012). 
Belief and attitude towards yoga may influence, participation in yoga and outcomes of yoga interventions. (Sohl et al., 2011) Determining students' perceptions about yoga would be a step to understand their decision to include yoga in practice and continue it in future.

In view of this, aim of this study was to identify the beliefs and attitudes of health science students about yoga and to determine the impact of short yoga intervention on students' perceptions about yoga with respect to future yoga practice.

\section{Specific Objectives:}

1. To identify perceived physical, psychological and overall benefits of yoga in $1^{\text {st }}$ year health science students.

2. To identify perceived physical, psychological and other barriers for yoga practice in $1^{\text {st }}$ year health science students.

3. To compare the attitudes in above mentioned areas before and after short yoga intervention.

\section{Methodology}

This study included students belonging to NKP Salve Institute of Medical Sciences, Vidya Shikshan Prasarak Mandal's (VSPM) Dental College and Research Center, VSPM College of Physiotherapy and Madhuritai Deshmukh College of Nursing, Nagpur, Maharashtra, India.

Institutional ethics committee approval was taken.

A structured questionnaire was designed incorporating relevant questions from several studies (Atkinson et al., 2009; Simard \& Henry, 2009; Sohl et al., 2009; Bansal et al., 2013) and validated by peer group and professionals in the field. Questionnaire consisted of 30 questions, divided into categories consisting demographic data, perceived physical benefits (4 factors), psychological benefits (8 Factors), overall benefits of yoga ( 3 factors), perceived barriers in yoga practice(12 factors) and motivation and future implications about yoga (3 factors).

Study population was $1^{\text {st }}$ year health science students (Medical: 116, Dental: 42, Physiotherapy: 31 and Nursing: 89 students) during the academic year 2013-2014( $N=278)$
The concept of the study was explained to the students and written informed consent was obtained. The questionnaires were distributed to the students in small groups one day before the intervention and their self-reported responses were collected.

The intervention comprised of 5 days yoga sessions ( 2 hours per day) at the beginning of the academic year. The yoga training was scheduled early in the morning so that it would not affect the regular teaching Programme. The sessions conducted by qualified yoga trainers included:

- Yogic Warming Up

- Micro exercises for the joints (Sukshma Vyayama)

- Yoga Postures (Yogasana): Pawanmuktasana, Bhujangasana, Shalabhasana, Dhanurasana, Makarasana, Markatasana, Mandukasana and Shavasana.

- Yogic Breathing Exercises: Kapalbhati, Anulom Vilom Pranayama, Bahya Pranayama, Bhastrika Pranayama, Udgeet Pranayama, Bhramari and Ujjayi pranayama

- Meditation

- Yogic Relaxation Technique Yoga Nidra

- Guidance on Healthy Lifestyle, Mind Management, Time Management and Importance of Yoga in Maintaining Physical, Mental Fitness and Holistic Wellbeing

Post Intervention questionnaire was administered and collected one day after the completion of intervention.

\section{Statistical Analysis}

Software "Epi- info version 6.04" was used for the analysis. Percentage analysis was done to determine the perceived benefits, barriers and future motivation for yoga practice. Dominant perceived benefits and barriers were identified by factors with highest percentage. Chi-square test was used to observe the differences between pre and post intervention values. A $p$ value $<0.01$ was accepted statistically significant. 


\section{Results and Discussion}

Out of total 278 students, $76.3 \%$ were females and $23.7 \%$ males. The mean age of the population was $18.5 y$ years. $39 \%$ students practiced yoga regularly. $32 \%$ practiced sometimes and the remaining $29 \%$ had no prior experience of yoga.

Students acknowledged various physical and psychological benefits of yoga. $97.2 \%$ students believed that yoga helps in keeping optimum fitness with balanced physical, mental and spiritual health. $94 \%$ students believed that they feel an overall sense of wellbeing. Simard (2009) also reported similar findings.

Dominant perceived physical benefits of yoga were flexibility $(97.3 \%)$, stamina $(94 \%)$ and optimum weight (96.3\%).

Relaxation (96.7\%), improved memory (95.9\%) and reduction in stress (92.1\%) were dominant perceived psychological benefits.

Time management (71.9\%) and lack of motivation $(65.1 \%)$ were perceived dominant barriers in practicing yoga. Similar findings were reported by (Sajwani et al., 2009) in a study carried out in Pakistan. There was no significant difference in the perceptions of students about yoga after intervention except perception about barriers such as time management and motivation for future yoga practice.

The statistically significant difference in pre and post intervention perception about time management and motivation ( $p$ value $<0.001$ ) suggests that these interventions should be regularly planned, with regular follow up to motivate, reinforce and manage time effectively.

\section{Future Implications}

There is a need to accentuate the importance of incorporating yoga in health science education that will be feasible to implement on a regular basis.

The regulatory bodies should consider including yoga in health science education curriculum.

\section{Table 1: Students' Perceptions about Yoga}

\begin{tabular}{|c|c|c|c|c|}
\hline Dominant Perceived Physical Benefits & $\begin{array}{l}\text { Pre \% } \\
\text { Yes }\end{array}$ & $\begin{array}{l}\text { Post \% } \\
\text { Yes }\end{array}$ & $P$ value & Chi square \\
\hline Improved body flexibility & 97.2 & 97.3 & 0.933 & 0.01 \\
\hline Improved physical stamina & 95.3 & 96.3 & 0.399 & 0.71 \\
\hline Maintaining optimum weight & 92.1 & 94 & 0.587 & 0.29 \\
\hline \multicolumn{5}{|l|}{ Dominant Perceived Psychological Benefits: } \\
\hline Improved memory & 94.2 & 95.9 & 0.417 & 0.66 \\
\hline Better relaxation and sleep & 93.1 & 96.7 & 0.076 & 3.13 \\
\hline Reduced anxiety and stress & 92.1 & 89.2 & 0.272 & 1.21 \\
\hline \multicolumn{5}{|l|}{ Perceived Overall Effects of Yoga } \\
\hline $\begin{array}{l}\text { Optimum fitness with balanced physical, mental and spiritual } \\
\text { health }\end{array}$ & 96.8 & 97.2 & 0.754 & 0.10 \\
\hline Overall sense of well being & 88.5 & 94 & 0.034 & 4.49 \\
\hline Improved academic performance & 82.7 & 89.9 & 0.021 & 5.26 \\
\hline \multicolumn{5}{|l|}{ Dominant Perceived Barriers in practicing Yoga } \\
\hline Lack motivation for practicing yoga & 65.1 & 41 & 0.00 & 28.54 \\
\hline Difficult to manage time & 71.9 & 56.8 & 0.00 & 12.17 \\
\hline Prefer other forms of exercise & 54.2 & 47.6 & 0.152 & 2.05 \\
\hline \multicolumn{5}{|l|}{ Motivation and Future implications } \\
\hline $\begin{array}{l}\text { Yoga should be included in health science education } \\
\text { curriculum }\end{array}$ & 80.6 & 88.7 & 0.014 & 6 \\
\hline Performing yoga in group will motivate me to do yoga & 89.4 & 87.6 & 0.549 & 0.36 \\
\hline $\begin{array}{l}\text { I will be more careful about balancing my exercise, diet and } \\
\text { relaxation }\end{array}$ & 93.1 & 93.9 & 0.729 & 0.12 \\
\hline
\end{tabular}


Longitudinal studies on impact of yoga intervention on students' perceptions and different physiological and psychological parameters are recommended for further research.

\section{Conclusion}

Health science students had overall positive attitude towards yoga and health. Short yoga interventions did not have significant impact on perceptions of students about benefits of yoga, but helped to overcome barriers by providing motivation and effective time management. Incorporating yoga in health science education will help future professionals to adopt positive health and disseminate the same to their patients and community.

\section{References}

Atkinson, N. L. \& Permuth-Levine, R. (2009) Benefits, barriers, and cues to action of yoga practice: a focus group approach, American Journal of Health Behaviour, 33, 1, pp.3-14.

Bansal, R., Gupta, M., Agarwal, B. \& Sharma, S. (2013) Impact of short term yoga intervention on mental well-being of medical students posted in community medicine: A pilot study, Indian Journal of Community Medicine, official publication of Indian Association of Preventive \& Social Medicine 38, 2, pp. 105.

Sajwani, R.A., Shoukat, S., Raza, R., Shiekh, M.M., Rashid, Q., Siddique, M.S., Panju, S., Raza, H., Chaudhry, S. \& Kadir, M.M. (2009) Knowledge and practice of healthy lifestyle and dietary habits in medical and non-medical students of Karachi, Pakistan, Journal of Pakistan Medical Association, 59, 9, pp.650.

Shankarapillai, R., Nair, M.A. \& George, R. (2012) The effect of yoga in stress reduction for dental students performing their first periodontal surgery: A randomized controlled study, International Journal of Yoga, 5, 1, pp.48.

Simard, A. A. \& Henry, M. (2009) Impact of a short yoga intervention on medical students' health: A pilot study, Medical Teacher, 31, 10, pp. 950-952.

Sohl, S.J., Schnur, J., Daly, L., Suslov, K. \& Mont gomery, G.(2011) Development of the beliefs about yoga scale, International Journal of Yoga Therapy, 21,1, pp.85-91. 